\title{
Distribution of bovine cysticercosis prevalence in the southeastern districts of Botswana from 2015 to 2016
}

\author{
Batatu Mazhani ${ }^{(D)}$, Elly Masitha ${ }^{1}$ (D) Mpho Ntwaetsile ${ }^{2}$, Ketshephaone Thutwa ${ }^{3}$ iD and Kerapetse Sehularo ${ }^{1}$ (D)
}

1. Department of Veterinary Sciences, Faculty of Animal and Veterinary Sciences, Botswana University of Agriculture and Natural Resources, Private Bag 0027, Gaborone, Botswana; 2. Meat Industry Training Institute, Faculty of Animal and Veterinary Science, Botswana University of Agriculture and Natural Resources, Private Bag 0027, Gaborone, Botswana;

3. Department of Animal Sciences, Faculty of Animal and Veterinary Science, Botswana University of Agriculture and Natural Resources, Private Bag 0027, Gaborone, Botswana.

Corresponding author: Batatu Mazhani, e-mail: bmazhani@buan.ac.bw

Co-authors: EM: emasitha@buan.ac.bw, MN: mntwaetsile@buan.ac.bw, KT: kthutwa@buan.ac.bw, KS: ksehularo@buan.ac.bw

Received: 26-08-2021, Accepted: 10-01-2022, Published online: 17-02-2022

doi: www.doi.org/10.14202/vetworld.2022.368-373 How to cite this article: Mazhani B, Masitha E, Ntwaetsile M, Thutwa K, Sehularo K (2022) Distribution of bovine cysticercosis prevalence in the southeastern districts of Botswana from 2015 to 2016, Veterinary World, 15(2): 368-373.

\begin{abstract}
Background and Aim: Bovine cysticercosis is defined as a foodborne parasitic zoonotic disease of cattle caused by the larval stage of the human tapeworm Taenia saginata. In Botswana, bovine cysticercosis has inflicted major economic consequences on the beef industry due to downgrading, condemnation, or treatment of infected carcasses. Thus, in this study, we aim to (1) estimate the prevalence of bovine cysticercosis in Botswana's southeastern districts, (2) describe the distribution of bovine cysticercosis through geospatial mapping, and (3) investigate the effect of seasonality on bovine cysticercosis occurrence.
\end{abstract}

Materials and Methods: A retrospective study was conducted using abattoir records of cattle slaughtered from August 2015 to July 2016. In total, 13 licensed non-export abattoirs were selected for this study, wherein 26,827 cattle were slaughtered during this period. Detection of cysticerci from the carcass and offal was carried out by meat inspectors visually during meat inspection. Prevalence of bovine cysticercosis was calculated for the extension areas and veterinary districts for each month and form there used to establish its distribution and seasonality. Data were analyzed using SPSS version 25.0.

Results: The prevalence of bovine cysticercosis in the southeastern districts of Botswana during this study period was determined to be $6.2 \%$. The prevalence in the veterinary districts differed significantly at $\mathrm{p}<0.05$. Seasonality did not have a significant $(\mathrm{p}=0.651)$ effect on the prevalence of bovine cysticercosis. Geospatially, areas with greater than $8 \%$ prevalence were mainly located in the southernmost part of the study area.

Conclusion: The prevalence of bovine cysticercosis was $6.2 \%$ during the study period. No previous studies on cysticerci prevalence in the study area was conducted; thus, it was not possible to determine whether there has been an increase or decrease in terms of prevalence rate. Therefore, the results of this study can be used as a baseline for the prevalence of cysticerci in the study area.

Keywords: bovine cysticercosis, prevalence, geospatial distribution, meat industry, seasonal occurrence.

\section{Introduction}

Bovine cysticercosis is described as a foodborne parasitic zoonotic disease of cattle caused by the larval stage of the human tapeworm Taenia saginata. The life cycle of the parasite occurs in both humans and cattle. The larvae are meat borne, and the adult stage develops only in the intestine of the human host (obligate). When expelled into the surrounding environment, infective eggs from humans can contaminate feed and water. On ingestion of infective eggs by a bovine (intermediate host), an embryo (or oncosphere)

Copyright: Mazhani, et al. Open Access. This article is distributed under the terms of the Creative Commons Attribution 4.0 International License (http://creativecommons.org/licenses/ by/4.0/), which permits unrestricted use, distribution, and reproduction in any medium, provided you give appropriate credit to the original author(s) and the source, provide a link to the Creative Commons license, and indicate if changes were made. The Creative Commons Public Domain Dedication waiver (http:// creativecommons.org/publicdomain/zero/1.0/) applies to the data made available in this article, unless otherwise stated. hatches from the egg and penetrates the host's intestinal mucosa to enter its circulatory system [1]. Once in the muscle or tissue, the embryo then develops into a cysticercus and becomes infective to a human host after about 10-12 weeks [1]. Detection of cysticerci in cattle is conducted through routine meat inspection. However, studies have shown that the prevalence estimates using this detection method underestimate parasite prevalence by a factor of at least 3-10 [2]. Cysticerci are found predominantly in cardiac and skeletal musculature, but occasionally in other sites, including liver, lungs, kidneys, and lymph nodes [1]. Surveillance of bovine cysticercosis through meat inspection is carried out in all licensed abattoirs in Botswana [3].

The detention or condemnation of meat due to cysticerci could often result in economic losses to all beefindustry players. The Botswana Meat Commission reported a loss of Botswana Pula (BWP) 83,648,504 
in 2013 due to refrigeration costs and decreased market value of infected carcasses [4]. Despite the considerable significance of this disease to the economy, the study studies on the epidemiology of bovine cysticercosis in Botswana have remained scarce $[5,6]$. In fact, in all of Southern Africa, studies examining the prevalence of this disease have remained to be limited [7-9].

Considering the major contribution of the beef subsector to Botswana's agricultural share of the country's gross domestic product [10], this study aimed to (1) determine the prevalence of bovine cysticercosis in Botswana's southeastern districts by examining records of cattle slaughtered from August 2015 to July 2016 in licensed non-export abattoirs, (2) describe the distribution of bovine cysticercosis through geospatial mapping, and (3) investigate the effect of seasonality on the occurrence of bovine cysticercosis. The results of this study can be used by government authorities and industry leaders as a guide for the implementation of strategies to prevent and control the spread of bovine cysticercosis.

\section{Materials and Methods}

\section{Ethical approval}

Ethical approval for this study was not required. Data used in this study were obtained from slaughter facilities licensed under the regulatory authority of the Department of Veterinary Services under the Ministry of Agriculture and Food Security. All slaughtering complied with animal welfare ethical requirements as stated in the standards, regulations, and laws of the Government of Botswana. Approval for the research was thus granted by the Director of Veterinary Services (Reference V 6/1/31 IV [19]).

\section{Study period, location, and sampling}

This study covered cattle slaughtered at licensed non-export abattoirs in the southeastern districts of Botswana from August 2015 to July 2016. These administrative districts are South, South East, Kweneng, and Kgatleng, covering nine veterinary districts Goodhope, Kanye, Jwaneng, Lobatse, Gaborone, Ramotswa, Mochudi, Molepolele, and Letlhakeng. Respective veterinary districts are further divided into extension areas. Human population for the respective veterinary districts in the study were Kanye $(47,007)$, Gaborone $(231,592)$, Jwaneng $(18,008)$, Molepolole $(66,466)$, Lobatse (29,007), Goodhope (6362), Mochudi $(44,815)$, Letlhakeng (7229), and Ramotswa $(28,952)$ [11].

A total number of 13 licensed non-export abattoirs were selected for the study. These abattoirs make up $76 \%$ of abattoirs operational during the study period. The catchment for the abattoirs is predominantly communal areas. Abattoirs excluded were those that slaughtered less that 5 cattle per week, those not operational during the study period, and those with unreliable and incomplete records.

Detection of cysticerci was performed according to the regulations set out by the Department of Veterinary Services (Republic of Botswana Laws,
2007). Information recorded in the abattoir records, although not standardized, included date of slaughter, district of origin, extension area of origin, total number of cattle slaughtered, total number of carcasses detected with cysticerci, total number of carcasses treated, and total number of carcasses condemned. The place of origin in terms of the veterinary district and extension area was of interest to our study. Cattle originating from veterinary districts outside of the study area were excluded in the analysis. The Botswana Animal Information and Traceability System was used in some instances to obtain missing information.

\section{Data collection}

Existing monthly abattoir records of cattle slaughtered were collected and analyzed to determine bovine cysticercosis prevalence; as per the data collected, 26,827 slaughtered cattle were recorded.

\section{Statistical analysis}

The prevalence was defined as the number of cattle identified as harboring cysticerci during meat inspection divided by the number of slaughtered cattle [12]. This was expressed as a percentage for each extension area and veterinary districts within the area of study. One-way analysis of variance in Statistical Package for the Social Sciences V 25.0 (IBM Corp., NY, USA) was used to determine whether bovine cysticercosis prevalence differed between veterinary districts of Botswana. As the data were not normally distributed, it was $\log _{10}$ transformed to approximate normality. Since there were data entries with values 1 was added to all the prevalence values before $\log _{10}$ transformations. However, the averages presented in the results section are untransformed. The GamesHowell post-hoc test was used to compare the means.

\section{Results}

The overall prevalence of bovine cysticercosis in the study area was $6.2 \%$. The prevalence for the respective administrative districts was observed to be $7.3 \%$ (South), 4.5\% (Kgatleng), 5.5\% (Kweneng), and $6.0 \%$ (Southeast).

\section{Prevalence rate in the veterinary districts}

The prevalence of bovine cysticercosis was noted to differ significantly $(\mathrm{p}=0.000)$ between the studied veterinary districts (Figure-1). As per our findings, Lobatse had the lowest prevalence (3.2\%), while Kanye had the highest prevalence $(9.3 \%)$ in the areas examined. According to our Games-Howellpost hoc analysis, Goodhope had a significantly higher bovine cysticercosis prevalence $(p=0.000)$ than Letlhakeng. The prevalence rate of this disease was also significantly higher in Kanye than in Letlhakeng $(\mathrm{P}=0.003)$ and Mochudi ( $\mathrm{P}=0.000$ ),

\section{Prevalence in extension areas}

The prevalence of bovine cysticercosis in extension areas was deemed significant $(\mathrm{p}=0.000)$. The prevalence was highest in Mmankgodi at $19 \%$ and lowest in Kokong and Morwamusu extension area at 
$0 \%$ (Table-1). Geospatial distribution demonstrated that most extension areas with high prevalence were concentrated in the Kanye district (Figure-2). In addition, the prevalence of bovine cysticercosis has progressively decreased east and west of the Kanye district (Figure-2).

\section{Prevalence of bovine cysticercosis in different months}

Overall, the month wherein a record was taken did not significantly affect $(\mathrm{p}=0.651)$ bovine cysticercosis prevalence in the study area. However, January had the lowest prevalence (3.9\%), whereas June had the highest prevalence rate (7.9\%) (Figure-3). Parasite prevalence during the wet season, from October to March, tended to be lower (5.7\%) than that of the dry season (6.8\%), from April to September.

\section{Discussion}

This study indicates that the overall mean prevalence of bovine cysticercosis in the southeastern districts of Botswana was $6.2 \%$ during the study period. No previously published bovine cysticercosis prevalence studies have been conducted in this study area,

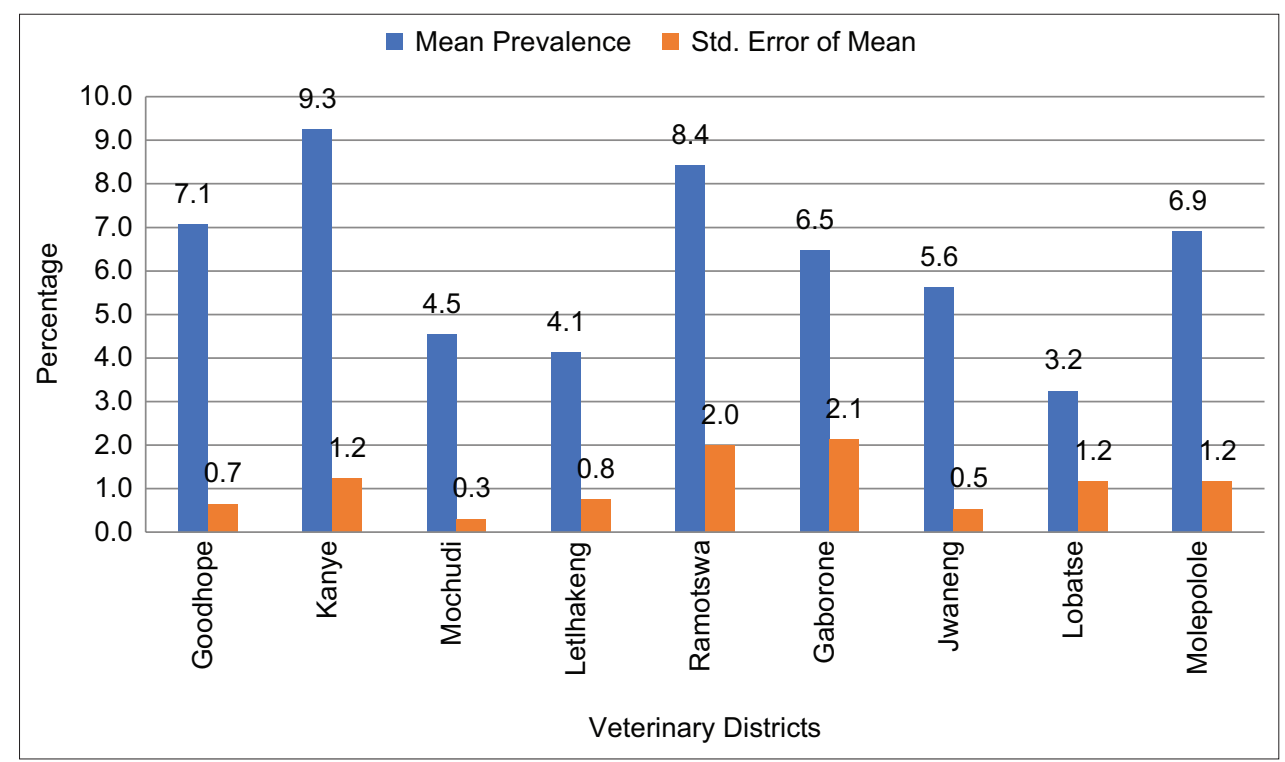

Figure-1: The mean prevalence of bovine cysticercosis in the veterinary districts $(n=9)$ with standard errors from 2015 to 2016 .

Table-1 : Mean prevalence of bovine cysticercosis in extension areas $(n=78)$ in the southeastern districts of Botswana.

\begin{tabular}{|c|c|c|c|c|c|}
\hline Extension area & Mean (\%) \pm S.E & Extension area & Mean (\%) \pm S.E & Extension area & Mean (\%) $(\%$ S.E \\
\hline Mmathethe & $7.888 \pm 0.572$ & Artesia & $5.282 \pm 1.202$ & Thankane & $3.207 \pm 1.722$ \\
\hline Metlobo & $8.790 \pm 2.118$ & Dikgonnye & $4.8000 \pm 1.076$ & Sekoma & $2.644 \pm 1.048$ \\
\hline Pitsane Molopo & $6.032 \pm 1.380$ & Oodi & $5.006 \pm 1.235$ & Maokane & $5.471 \pm 1.236$ \\
\hline Mokatako & $10.604 \pm 2.951$ & Leshibitse & $6.072 \pm 1.222$ & Mokhomma & $8.238 \pm 1.901$ \\
\hline Pitsane & $3.897 \pm 2.036$ & Ramotlabaki & $3.775 \pm 1.252$ & Jwaneng & $9.578 \pm 3.443$ \\
\hline Digawana & $10.810 \pm 3.440$ & Olifantsdrift & $3.132 \pm 0.897$ & Samane & $6.662 \pm 1.557$ \\
\hline Ramatlabama & $2.543 \pm 1.362$ & Maboane & $5.562 \pm 1.623$ & Sese & $7.737 \pm 1.481$ \\
\hline Pelotshetlha & $7.727 \pm 2.971$ & Moshaweng & $6.315 \pm 4.177$ & Tsonyane & $8.281 \pm 2.234$ \\
\hline Goodhope & $5.452 \pm 1.506$ & Ngware & $5.786 \pm 3.952$ & Keng & $2.850 \pm 1.027$ \\
\hline Hebron & $7.912 \pm 1.936$ & Ditshegwane & $0.571 \pm 0.571$ & Khakhea & $4.732 \pm 2.168$ \\
\hline Mabule & $6.210 \pm 1.231$ & Salajwe & $4.284 \pm 3.822$ & Kokong & $0.000 \pm 0.000$ \\
\hline Moshupa & $15.010 \pm 3.627$ & Kudumelapye & $5.251 \pm 2.374$ & Morwamusu & $0.000 \pm 0.000$ \\
\hline Gasita & $4.363 \pm 1.542$ & Letlhakeng & $7.323 \pm 3.227$ & Lobatse & $3.250 \pm 1.170$ \\
\hline Kanye & $13.213 \pm 3.315$ & Dutlwe & $4.227 \pm 2.281$ & Gabane & $4.124 \pm 1.116$ \\
\hline Segwagwa & $10.746 \pm 2.546$ & Monwane & $1.122 \pm 1.122$ & Mogoditshane & $4.436 \pm 2.152$ \\
\hline Molapowabojang & $9.908 \pm 4.254$ & Sorilatholo & $10.000 \pm 5.774$ & Lephepe & $14.679 \pm 5.892$ \\
\hline Ranaka & $11.950 \pm 8.111$ & Takatokwane & $3.472 \pm 2.261$ & Medie & $5.425 \pm 1.782$ \\
\hline Sesung & $4.901 \pm 2.885$ & Botlhapatlou & $0.760 \pm 0.760$ & Boatlaname & $12.754 \pm 8.899$ \\
\hline Lorolwane & $2.911 \pm 1.570$ & Motokwe & $1.335 \pm 0.901$ & Lentsweletau & $2.255 \pm 1.827$ \\
\hline Pitseng & $11.267 \pm 2.408$ & Mogobane & $10.058 \pm 4.268$ & Hatsalatladi & $12.307 \pm 6.613$ \\
\hline Selokolela & $9.857 \pm 4.075$ & Otse & $3.175 \pm 1.762$ & Kopong & $3.333 \pm 3.333$ \\
\hline Kgomodiatshaba & $7.436 \pm 0.772$ & Ramotswa & $11.916 \pm 3.427$ & Thamaga & $3.175 \pm 2.100$ \\
\hline Bokaa & $3.955 \pm 0.806$ & Gaborone & $10.490 \pm 3.569$ & Mmankgodi & $19.033 \pm 4.807$ \\
\hline Mochudi & $4.757 \pm 0.779$ & Tlokweng & $2.774 \pm 2.047$ & Sojwe & $3.634 \pm 1.987$ \\
\hline Malolwane & $3.260 \pm 0.797$ & Mahotshwane & $5.480 \pm 1.379$ & Kubung & $9.109 \pm 2.627$ \\
\hline Malotwane & $2.537 \pm 0.550$ & Mabutsane & $7.414 \pm 2.317$ & Molepolole & $4.029 \pm 3.183$ \\
\hline
\end{tabular}




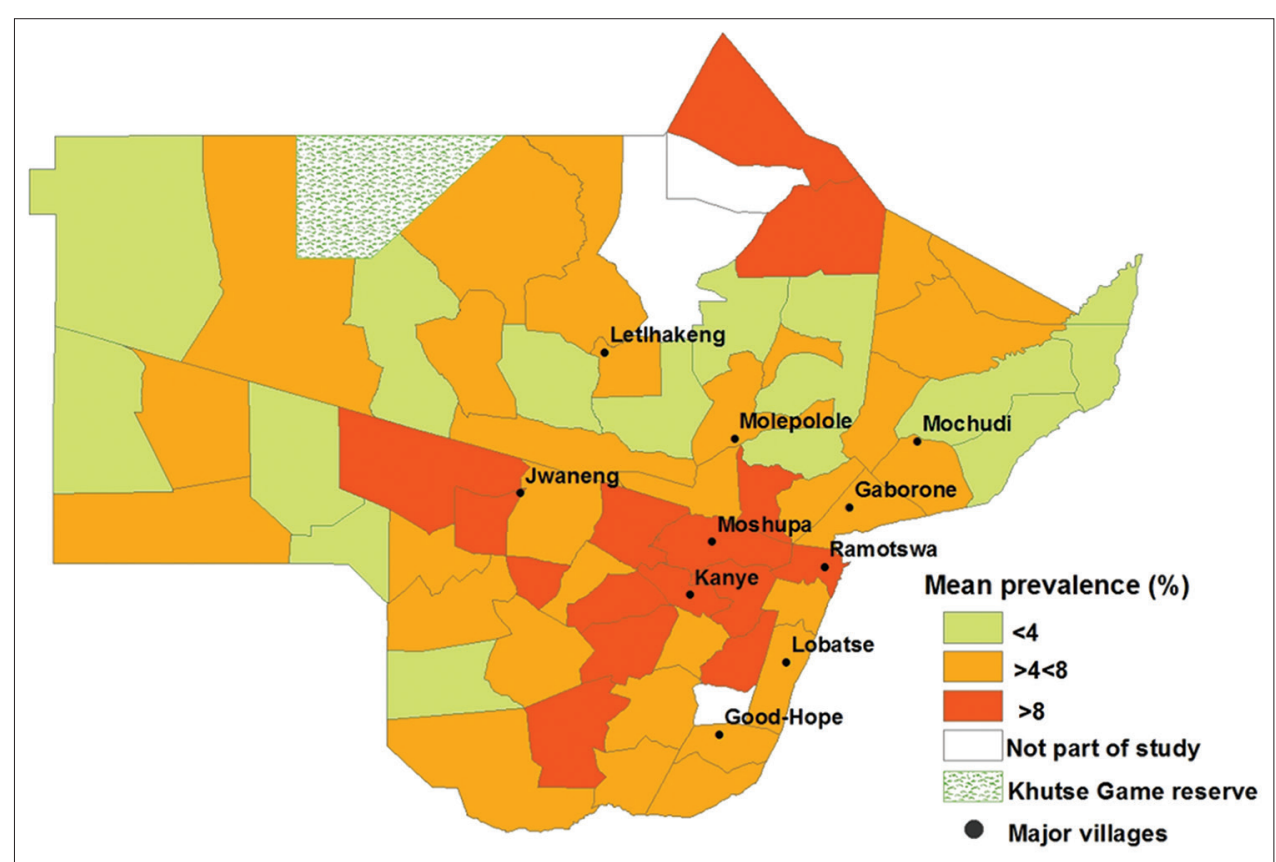

Figure-2: Geospatial distribution of the mean prevalence of bovine cysticercosis in extension areas $(n=78)$ in the southeastern districts of Botswana from 2015 to 2016 [Source: Department of Veterinary Services, IT Department. Graphics program: ArcGIS 10.4].

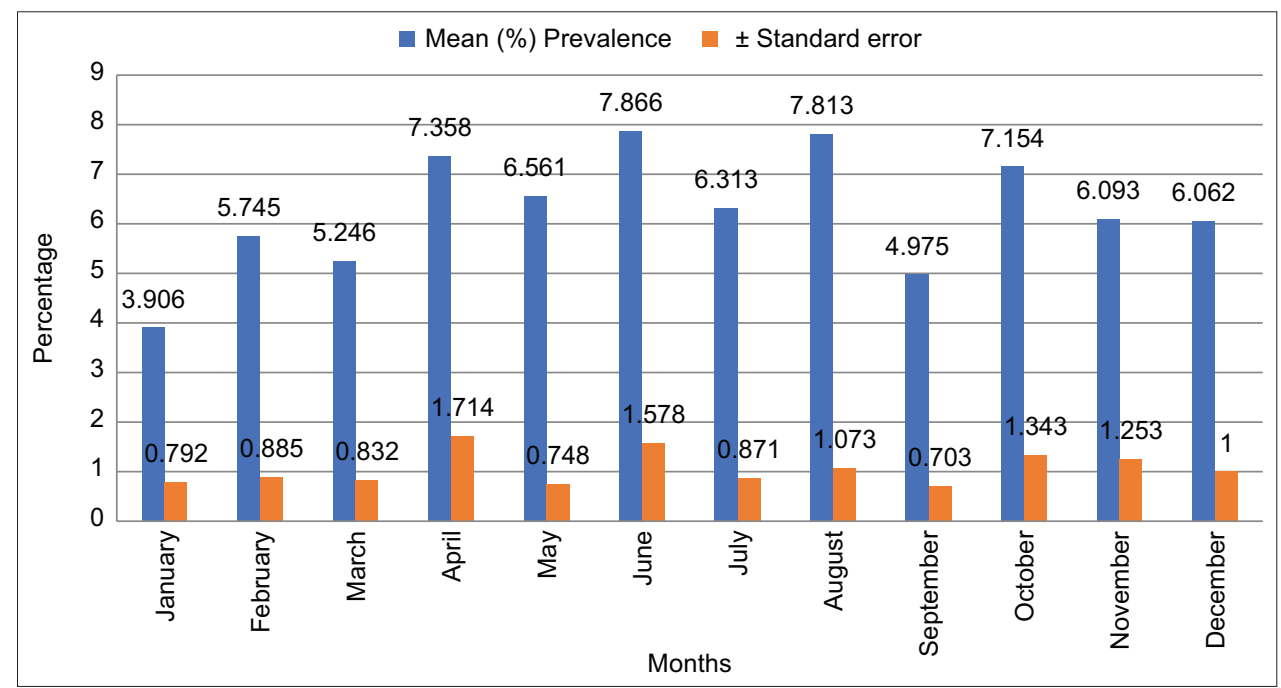

Figure-3: Monthly mean percentage prevalence of bovine cysticercosis in the southeastern districts of Botswana from 2015 to 2016.

to which we can compare the results of our study. However, a bovine cysticercosis incidence survey was previously performed using 10-year data from across Botswana collected by the export abattoir Botswana Meat Commission [5]. In that study, bovine cysticercosis incidence ranged from $12 \%$ to $15 \%$.

The bovine cysticercosis prevalence in our study was higher than that of other African countries. A prevalence of $0.7 \%$ was reported in South Africa [8], 1.6\% in Zimbabwe [9] and Egypt [13], and $2.6 \%$ in Ethiopia [14]. Conversely, this study's prevalence rate was lower than that in a study conducted in East Ethiopia where disease prevalence was at $19.7 \%$ [15].
The prevalence of bovine cysticercosis in this present study was also higher than that of countries outside of Africa, namely, Iran (1.71\%) [12], Brazil $(0.41 \%)$ [16], France $(0.142 \%)$ [17], and Denmark $(0.06 \%)$ [18].

Bovine cysticercosis prevalence in the Kgatleng administrative district was lower than in the other administrative districts. This is possibly due to farmers' awareness of Taenia saginata control measures and a generally positive attitude toward prevention and control of this disease in the district [6].

This study has also revealed that the prevalence rates of bovine cysticercosis in Kanye, Goodhope, and 
Ramotswa veterinary districts are higher than that of Gaborone, which is in contrast to the results from Rossi et al. [19], who found that densely human populated areas had higher bovine cysticercosis prevalence. One possible explanation for this conflicting result is that Gaborone, as a city, has good sewage and sanitation systems and thus has a minimized risk of environmental contamination; also, Gaborone has low cattle populations. On the other hand, Kanye, Goodhope, and Ramotswa, as villages, have poorly developed sewage systems and high cattle populations in close proximity to humans, which could be possible risk factors for the high occurrence rate of bovine cysticercosis [20]. Furthermore, the Kanye veterinary district is often used for leisure activities that occur in cattle pastures where sanitation systems are poor, posing a higher risk for contracting bovine cysticercosis [20].

Although not statistically significant, prevalence during the wet seasons (November-March) was slightly lower than that during the dry seasons. These findings were consistent with other studies carried out in countries with similar climatic conditions as those in the study area $[8,9]$. The slight differences in prevalence may be due to the effect of temperature and humidity on the survivability of $T$. saginata eggs [21]. Damp and temperate climates provide hospitable conditions for $T$. saginata eggs for roughly 10 months [1]. Climatic conditions in Botswana during the wet season are characterized by high temperatures that potentially impact the survivability of $T$. saginata eggs. In contrast, an increase in bovine cysticercosis incidence during drought season has been attributed to high cattle-human contact caused by competition for water between humans and livestock [5].

\section{Conclusion}

Bovine cysticercosis prevalence in Botswana's southeastern districts was high $(6.2 \%)$ relative to Zimbabwe and South Africa and thus warrants immediate action. Since there is no record of previous prevalence studies from Botswana, the results of this study can be used as a baseline for futureresearch in the study area. Furthermore, our results will be valuable for informing governmentfor the policies and providing information on where to target intervention measures in the control and prevention of bovine cysticercosis. As illustrated geospatially, priority areas should be those with a prevalence rate greater than $8 \%$. Finally, future epidemiological studies to determine the local risk factors within different veterinary districts should be considered, as this was not evaluated in the present study.

\section{Authors' Contributions}

BM, EM, and KS: Conceived and designed the study. MN: Collection of data. BM and EM: Interpreted results and revised map. KT: Analyzed the data and revised the manuscript. BM: Drafted and revised the manuscript. All authors have read and approved the final manuscript.

\section{Acknowledgments}

The authors thank the Director of the Department of Veterinary Services, Ministry of Agricultural Development and Food Security, Botswana, for granting us permission to use their data. The authors are thankful for the Botswana Animal Information and Traceability System technical officers who produced the distribution map. The authors also thank the Botswana University of Agriculture and Natural Resources for funding the publication of this manuscript.

\section{Competing Interests}

The authors declare that they have no competing interests.

\section{Publisher's Note}

Veterinary World remains neutral with regard to jurisdictional claims in published map and institutional affiliation.

\section{References}

1. WHO/FAO/OIE. (2005) Guidelines for the Surveillance, Prevention and Control of Taeniosis/Cysticercosis, World Health Organisation (WHO)/Food and Agriculture Organisation (FAO)/World Organisation for Animal Health (OIE), Paris, France. Available from: https://www. who.int/taeniasis/resources/9290446560/en Retrieved on 20-08-2019.

2. European Union. (2000) Opinion of the Scientific Committee on Veterinary Measures Relating to Public Health on the Control of Taeniosis/Cysticercosis in Man and Animals. Available from: http://www.europa.eu.int/comm/ food/fs/sc/scv/out36_en.pdf Retrieved on 20-08-2019.

3. Republic of Botswana Laws. (2007) Livestock and Meat Industries Chapter 36: 03. Botswana Government Printers.

4. Anonymous. (2015) The Strategy for the Control of Measles and Human Tapeworm in Botswana. Draft Version 1.1. Ministry of Agriculture, Botswana.

5. Mosienyane, M.G. (1986) A survey of Cysticercus bovis (measles) infestation in cattle sent for slaughter to Botswana Meat Commission (BMC); a ten years retrospective study 1974-1983. Int. J. Zoonoses, 13(2): 124-130.

6. Oladele, O.I. and Lesotho, K. (2010) Determinants of cattle farmers' awareness and attitude towards prevention and control of Cysticercus bovis in Botswana. Livest. Res. Rural Dev., 22(10), Article\#177. Available from http://www.lrrd. org/lrrd22/10/olad22177.htm. Retrieved on 06-03-2020,

7. Dorny, P., Phiri, I., Gabriel, S., Speybroeck, N. and Vercruysse, J. (2002) A sero-epidemiological study of bovine cysticercosis in Zambia. Vet Parasitol., 104(3): 211-215.

8. Qekwana, D.N., Oguttu, J.W., Venter, D. and Odoi, A. (2016) Disparities in beef tapeworm identification rates in the abattoirs of Gauteng Province, South Africa: A descriptive epidemiologic study. PLoS One, 11(3): e0151725.

9. Sungirai, M., Masaka, L. and Mbiba, C. (2014) The prevalence of Taenia saginata cysticercosis in the Matabeleland provinces of Zimbabwe. Trop. Anim. Health Prod., 46(4): 623-627.

10. United Nations Development Programme (UNDP). (2015) Botswana's GDP 2015. Available from: https://www.undp. $\mathrm{org} /$ content/dam/botswana/docs/publications/botswana\%60s\%20gdp\%202015.pdf Retrieved on 21-08-2019.

11. Statistics Botswana. (2014) Population and Housing Census 2011 Dissemination Seminar. Available from: http:// www.statsbots.org.bw/sites/default/files/publications/ 
population $\% 20$ and $\% 20$ housing $\% 20$ census $\% 202011 \% 20$ $\%$ 20dissemination\%20seminar\%20report.pdf Retrieved on 24-09-2019.

12. Dupuy, C., Morlot, C., Gilot-Fromont, E., Mas, M., Grandmontagne, C., Gilli-Dunoyer, P., Gay, E. and Callait-Cardinal, M.P. (2014) Prevalence of Taenia saginata cysticercosis in French cattle in 2010. Vet. Parasitol., 203(1-2): 65-72.

13. Abdo, B.R.N., Sayed, A.S.M., Hussein, A.A.A. and Arafa, M.I. (2009) Occurrence of cysticercosis in cattle and buffaloes and Taenia saginata in man in Assiut Governance of Egypt. Vet. World., 2(5): 173-176.

14. Teklemariam, A.D. and Debash, W. (2015) Prevalence of Taenia saginata/cysticercosis and community knowledge about zoonotic cestodes in and around Batu, Ethiopia. $J$. Vet. Sci. Technol., 6(6): 273.

15. Terefe, Y., Redwan, F. and Zewdu, E. (2014) Bovine cysticercosis and its food safety implications in Harari People's National Regional State, eastern Ethiopia. Onderstepoort J. Vet. Res., 81(1): 676.

16. Mirzaei, M., Nematolahi, A., Ashrafihelan, J. and Rezaei, H. (2016) Prevalence of infection with the larval form of the cestode parasite Taenia saginata in cattle in Northwest Iran and its zoonotic importance. Turkiye Parazitol. Derg., 40(4): 190-193.
17. Comin, V.C., Mathias, L.A., Almeida, H.M.S. and Rossi, G.A.M. (2021) Bovine cysticercosis in the state of São Paulo, Brazil: Prevalence, risk factors and financial losses for farmers. Prev. Vet. Med., 191: 105361.

18. Calvo-Artaviaa, F.F., Nielsena, L.R., Dahlb, J., Clausena, D.M. and Alban, L. (2013) Occurrence and factors associated with bovine cysticercosis recorded in cattle at meat inspection in Denmark in 2004-2011. Prev. Vet. Med., 110(2): 177-182.

19. Rossi, G.A.M., Simoni, H.A.S., Lopes, W.D.Z., Almeida, H.M.S, Soares, V.E., Vidal, A.M.C., Ferraudo, A.S. and Mathias, L.A. (2016) Prevalence and geospatial distribution of bovine cysticercosis in the state of Mato Grosso, Brazil. Prev. Vet. Med., 130: 94-98.

20. Marshalla, L.R., Chengat Prakashbabua, B., Pinto Ferreirab, J., Buzdugana, S.N., Stärk, K.D.C. and Guitiana, J. (2016) Risk factors for Taenia saginata cysticercus infection in cattle in the United Kingdom: A farmlevel case-control study and assessment of the role of movement history, age and sex. Prev. Vet. Med., 135: 1-8.

21. Jansen, F., Dorny, P., Gabriël, S., Dermauw, V., Vang Johansen, M. and Trevisan, C. (2021) The survival and dispersal of Taenia eggs in the environment: What are the implications for transmission? A systematic review. Parasit. Vectors, 14(1): 88 . 